\title{
Patterns of asymmetry in body traits and genitalia in two distant populations of a Neotropical scorpion
}

\author{
P.A. Olivero*, D.E. Vrech, A.V. Peretti and C.I. Mattoni \\ Laboratorio de Biología Reproductiva y Evolución, Instituto de Diversidad y Ecología Animal \\ (IDEA, CONICET), Facultad de Ciencias Exactas, Físicas y Naturales, Universidad Nacional \\ de Córdoba, Córdoba, Argentina
}

(Received 26 November 2013; accepted 17 June 2014; first published online 3 September 2014)

\begin{abstract}
The ability of a genotype to control the stable development of a phenotype under different environmental conditions may explain the level of developmental instability. An indicator to developmental instability is Fluctuating Asymmetry. Traits under pressures of sexual selection exhibit greater values of asymmetry that others. These traits have more physiological requirements during morphogenesis and a more complex development. The aims of this work are to analyze asymmetry patterns of genitalic and somatic traits in the scorpion Bothriurus bonariensis (Bothriuridae) and to compare these values between central and peripheral populations of its distribution. We observed that types of asymmetry in genitalic traits differed in both populations. Also, traits of the hemispermatophores (two halves that constitute the spermatophore) showed the highest levels of fluctuating asymmetry, particularly in those characteristics with important role for insemination success. This work offers fundamental baseline knowledge for further works focused on asymmetry of genitalia and mating success in scorpions.
\end{abstract}

Keywords: arachnids; Bothriurus bonariensis; developmental instability; selective pressure; South America

\section{Introduction}

Stress can be characterized as a force shaping adaptation and evolution in changing environments, and it is a property of both the stressor and the stressed (Bijlsma and Loeschcke 2005). Stressful conditions of the environment on the physiology of a species may limit the distribution range of the species. In many species, peripheral populations suffer stressful environmental conditions, and in this context, high metabolic costs are enough to limit expansions of their living range (McNab 1973; Root 1988a, 1988b; Alerstam 1990; Dennis 1993). Environmental conditions restrict species distribution range not only physiologically but also genetically (Møller and Swaddle 1997; Kark et al. 2004). The ability of a genotype to control the stable development of a phenotype under a range of environmental conditions may explain the level of developmental stability of a particular trait (Moller et al. 1995). A wide variety of environmental and genetic factors may result in a reduction of the developmental stability that makes individuals less efficient in terms of growth, survival and reproduction (Graham et al. 2000; Santos et al. 2006; Vishalakshi and Singh 2008a, 2008b).

\footnotetext{
*Corresponding author. Email: paoolivero@gmail.com
} 
A measure of developmental instability is fluctuating asymmetry, which is defined as small random differences between left and right sides of a bilateral trait. Indeed, this is a result of the inability of individuals to undergo identical development of both sides of a bilaterally symmetrical trait (Palmer and Strobeck 1992; Møller and Pomiankowski 1993; Swaddle et al. 1994; Møller 1997; Peretti et al. 2001; Leung et al. 2003; Helle et al. 2011). When an individual faces a sub-optimal set of environmental conditions, the developmental process becomes unstable and the levels of fluctuating asymmetry grow (Vishalakshi 2011). Other forms of asymmetry that can occur are Directional Asymmetry and Antisymmetry. The former occurs when there is a tendency for one side of an organism to develop more than the other (Van Valen 1962). In contrast, Antisymmetry shows one side of a character larger than the other but not handed-bias as to which side of the character will be bigger (TimofeeffRessovsky 1934; Graham et al. 1993, 2000; Palmer 2004, 2005). Fluctuating asymmetry is widely used to assess developmental instability; great differences appear in some fluctuating asymmetry values of different populations of a species (Picton et al. 1990; Moller 1993), as well as in the periphery of a distribution range (Parsons 1993; Kark 2001). In addition, traits influenced by sexual selection may exhibit greater values of fluctuating asymmetry in comparison with other traits in which such type of selection does not occur (Moller and Eriksson 1994; Peretti et al. 2001; Santos 2001; Uetz et al. 2009). An explanation for this trend is that many traits under sexual selection have more physiological requirements during morphogenesis and a more complex development (Pomiankowski et al. 1991).

Developmental instability has been explored in a wide variety of taxa (Lens and Van-Dongen 2000; Hendrickx et al. 2003; Vishalakshi and Singh 2008a, 2008b, 2008c; Băncilă et al. 2010; Helle et al. 2011). In arthropods, Huber et al. (2007) make an interesting review on genitalic evolution in spiders and insects, focusing on conspicuous asymmetry of sexual traits rather than minor random changes like fluctuating asymmetry. Among insects, fluctuating asymmetry patterns are not uniform. For example, in crickets and beetles habitat fragmentation is unrelated to fluctuating asymmetry (Berggren 2005; Henríquez et al. 2009). On the other hand, in Drosophila fluctuating asymmetry increases because of the influence of environmental stressors (Graham et al. 2000; Santos et al. 2006; Vishalakshi and Singh 2008a, 2008b).

Among arachnids, scorpions are a good model to study fluctuating asymmetry, in particular in genitalic traits. They show indirect sperm transfer by a sclerotized spermatophore. The spermatophore consists of two halves (hemispermatophores) produced by the male's paraxial organs. These two halves join to exit through the gonopore to form the spermatophore, immediately prior to sperm transfer (Hjelle 1990). So, if the two halves are developed differently, the spermatophore will show more asymmetry. This spermatophore is relatively complex and, from previous studies, it is know that certain structures may vary in size and shape (Peretti 1993). Peretti et al. (2001) examined some patterns of asymmetry in sexual and non-sexual traits in a population of Bothriurus bonariensis (Bothriuridae). This species has a wide distribution in South America, ranging from southeast Brazil to central Argentina, with a core population in Uruguay (Mattoni and Acosta 2005; Ojanguren Affilastro 2005). In Argentina, B. bonariensis inhabits the provinces of Entre Ríos, Corrientes, Buenos Aires, Santa Fe, La Pampa, Córdoba and San Luis. This area belongs to 'the Pampa' and 'the Espinal' phytogeographic provinces (Ojanguren Affilastro 2005) (Figure 1), both showing different environments depending on vegetation, soil and 


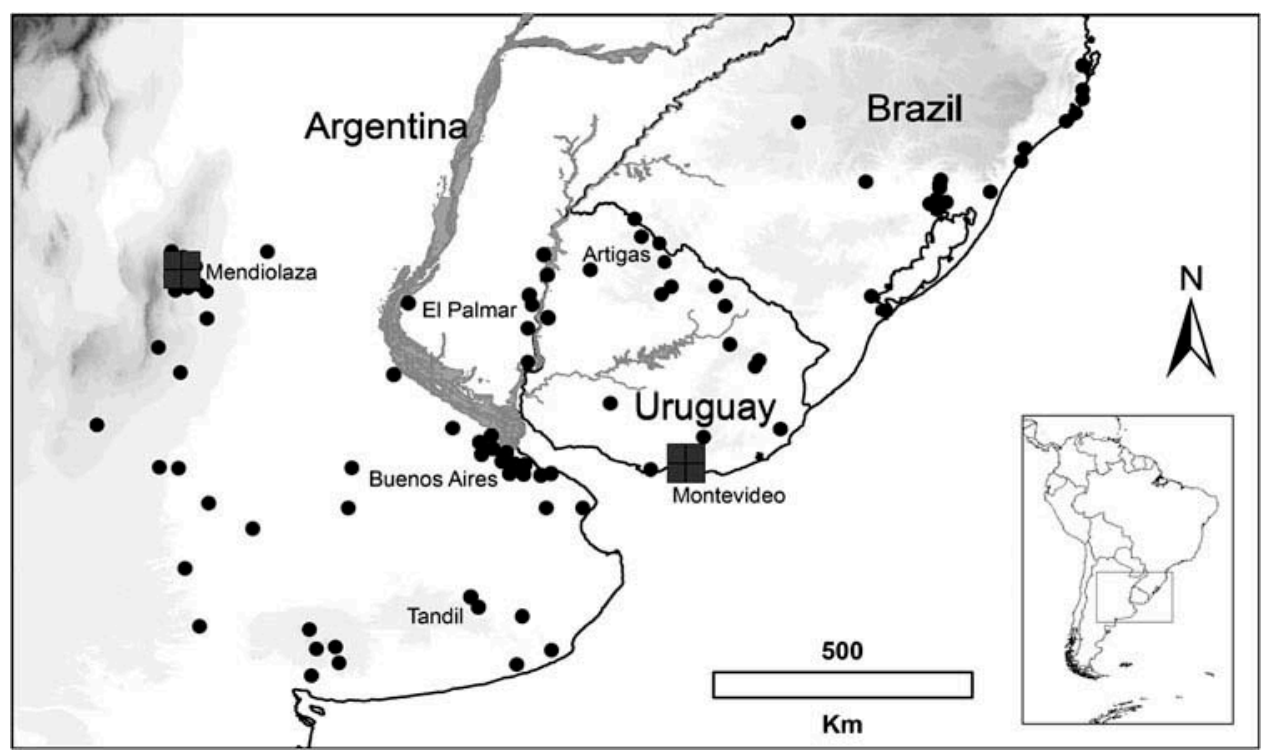

Figure 1. Geographic distribution of Bothriurus bonariensis. Black circles indicate the total distribution of the species known to date; grey grid squares show the populations used in this study.

climate (Cabrera and Willink 1973), factors that could affect development in this population on different ways (Kark et al. 2004; Olivero et al. 2012). The habitat of the Mendiolaza population (peripheral population in Córdoba Province) belongs to the phytogeographical province of the Espinal, while the Piedras de Afilar population (core population in Uruguay) corresponds to the phytogeographical province of Pampa. In comparison, the climate is wetter in the latter with a greater level of rains and lower temperatures (Cabrera and Willink 1973; Argentina's national meteorological service -online www.smn.gov.ar-; Uruguay's National direction of meteorology -online www.meteorologia.com.uy) (Figure 2).

Along its distribution, populations of this species show differences in colouring patterns and a wide range of sizes in morphological and sexual traits (Ojanguren Affilastro 2005; Olivero et al. 2012). This variation could be related to environmental characteristics that change throughout the species' range. Scorpion species belonging to wet zones show a greater amount of pigment than species inhabiting drier zones (Lourenço and Cloudsley-Thompson 1996; Mattoni 2002).

The aims of this work are to detect and analyze asymmetry patterns of genitalic and somatic traits in the scorpion Bothriurus bonariensis (Bothriuridae) and to compare these values between two different populations (central and peripheral) of its distribution. Our study focuses on two principal lines: (1) Given that the peripheral population may suffer more stressful conditions compared with core populations (Moller 1995; Auffray et al. 1999), we would expect to observe higher levels of asymmetry in the peripheral population; (2) Since traits under sexual selection tend to show higher levels of fluctuating asymmetry due to a higher sensitivity and physiological requirements for development (Pomiankowski et al. 1991), we would expect to find higher levels of asymmetry in spermatophore and sexually selected traits in comparison with other body traits. 

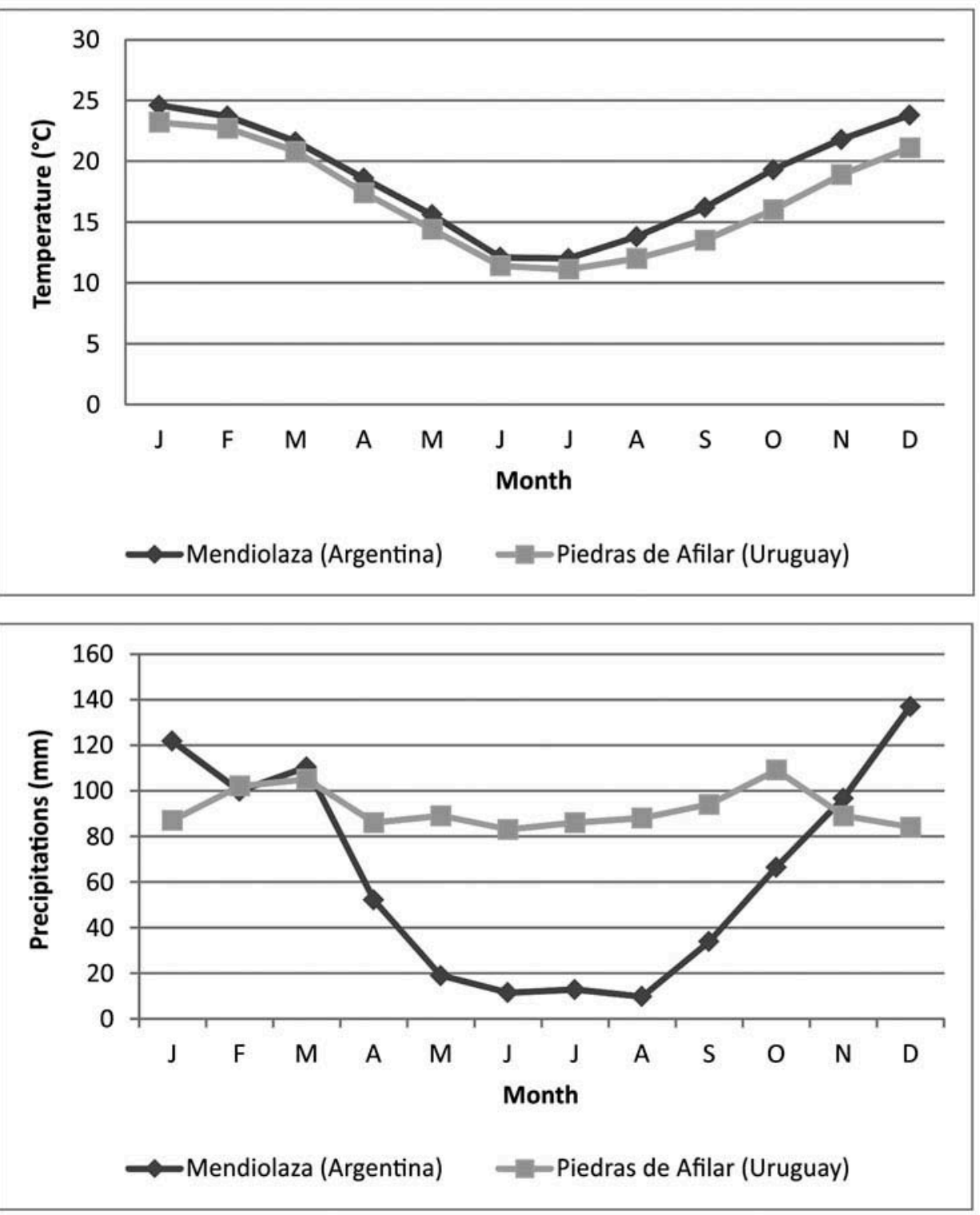

Figure 2. Mean temperature and annual rainfall in Mendiolaza (Argentina) and Piedras de Afilar (Uruguay) during 2010-2011.

\section{Materials and methods}

\section{Study material}

We analyzed specimens of $B$. bonariensis from two distant populations selected in order to represent the core and periphery of their distribution (Figure 1). We selected populations from which specimens were abundant (allowing statistical comparisons) and well preserved (poor preservation alters the hemispermatophore form) (Olivero 
et al. 2012). Selected populations were the following. Core population: Piedras de Afilar (Canelones province, Uruguay - 34²4'0,44” S, 55³1'59,79” W, 40 m.a.s.1), 16 males, 10 females, 16 pair of hemispermatophores; Peripheral population: Mendiolaza (Córdoba Province, Argentina - 31 ${ }^{\circ} 15^{\prime}$ 52,59” S, 6418'10" W, $540 \mathrm{~m}$. a.s.1), 20 males, 11 females, 20 pairs of hemispermatophores (Figure 1). The Mendiolaza population was considered the peripheral population because of its location and also by the climatic conditions of the area, which has an arid climate with high temperatures and low humidity. By contrast, the Piedras de Afilar population lives in a wetter and cooler climate with more favourable conditions (Figure 2), therefore was considered the core population, although this is not exactly located in the centre of the total distribution of the species (Cabrera and Willink 1973; Argentina's national meteorological service -online www.smn.gov.ar-; Uruguay's National direction of meteorology -online www.meteorologia.com.uy).

\section{Measurements of individuals}

To compare different populations of $B$. bonariensis, we followed the biological species concept (Mayr 1942). Although it is known that individuals of these two populations have significant morphological differences (Mattoni 2003; Ojanguren Affilastro 2005; Olivero et al. 2012) and probably could be considered as different species, this separation is not yet confirmed. For this reason, we consider these populations as one species. All study specimens were preserved in $80 \%$ ethanol. Both hemispermatophores from each male specimen were removed, cleaned by hand and preserved following Sissom et al. (1990). Morphological traits were measured in males and females and genitalic traits corresponded to both hemispermatophores (Peretti et al. 2001). The female has an ovoid and flexible genital atrium and two spermathecae which increase in size with successive inseminations (Peretti 2003). These traits were not included in this work because their elasticity makes confident measurements difficult. Sixteen traits were analyzed in males (four morphological and 12 from hemispermatophores) and four traits in females (Figure 3). Some measurements
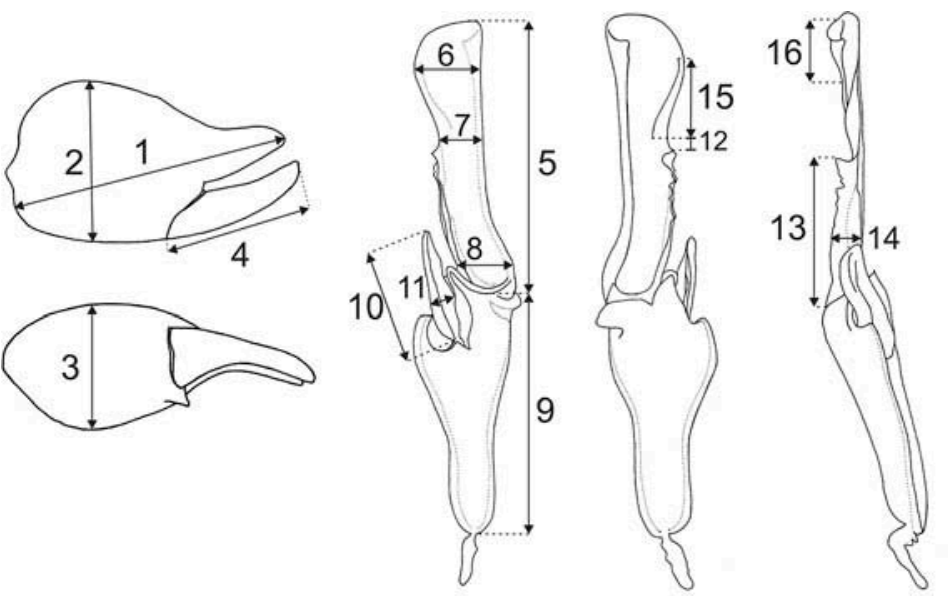

\section{REFERENCES}

1. Hand length

2. Hand height

3. Hand width

4. Movable finger length

5. Lamina length

6 . Lamina width (distal)

7. Lamina width (medial)

8. Lamina width (basal)

9. Trunk length

10. Capsular lobe length

11. Capsular lobe width

12. Distance of

dorsal fold-lateral edge

13. Dorsal fold length

14. Dorsal fold width

15. Lateral edge length

16. Crest length

Figure 3. Body and genitalic traits measured in males and females of Bothirurus bonariensis. 
were also used in a systematic study of Bothriuridae and for the description of spermatophores and hemispermatophores (Acosta 1989; Peretti 1992, 1993, 1995). Moreover, they are characters that have relevance in the context of sexual biology in general (Peretti 1992; Peretti et al. 2001; Peretti 2003). Each trait was measured twice by only one person, in order to compensate for measuring errors. Fluctuating asymmetry can be confused by measurement error, therefore repeat measurement should be undertaken to ensure that fluctuating asymmetry is detectable (Palmer and Strobeck 2003). Specimens were analyzed using a stereoscopic dissecting microscope (Nikon SMZ1500), and pictures were taken using a digital camera (Nikon Digital Sight DS-Fi1). Digital pictures were analyzed with the Image Tool 3.0 measuring software (C) UTHSCSA 1996-2002).

\section{Statistical analyses and types of asymmetry}

Statistical analyses were performed with the PC program NCSS 2007 (C) Hintze 2007). To control for measurement errors, a repeated measures ANOVA was used. All measurements of the variables were significantly repeatable (Table 1 in Appendix). For analyses and evaluation of the magnitude of asymmetry of each trait, the absolute level of asymmetry was estimated as the unsigned left-minusright character value. Relative asymmetry was estimated as absolute asymmetry divided by the mean left and right character value. Results are expressed as percentage of relative asymmetry (relative asymmetry value was multiplied by 100). To test if the signed left-minus-right character value fit a normal distribution, Shapiro-Wilks and Kolmogorov-Smirnov one-sample tests were used (Siegel and Castellan 1988). One-sample $t$-test was employed to establish the presence of directional asymmetry to data with normal distribution. Data with non-normal distribution were considered antisymmetry. To control the relationship between the absolute asymmetry and the mean size of sides (left and right) a linear regression analysis was performed. Three linear regressions were performed for individuals of each of the populations considering the traits showing higher levels of asymmetry: width of capsular lobe, length of lateral edge and length of crest. In each regression, independent variable was the size of the feature, and dependent variable was the absolute value of absolute asymmetry in the trait.

\section{Multivariate analyses}

To compare relative asymmetry of selected traits between the core and peripheral populations, we performed a multivariate discriminant analysis (Fisher 1936; Fukunaga 1990; Duda et al. 2001). Discriminant analysis results in a set of prediction equations (linear functions) based on independent variables that are used to classify individuals into groups. As an estimating method, the discriminant lineal function was used without setting a priori probabilities and without selecting variables. Canonical Correlation Coefficient and Wilks' Lambda Statistical were calculated, which allowed us to choose the most appropriate model for all models that can be constructed from the variables previously selected. Both ratios measure the differences between the groups due to discriminant functions (El Ouardighi et al. 2007). This technique allowed us to analyze if there was a separation among populations 
considering the studied variables and to determine the influence of each variable on the population discrimination level (Brown and Wicker 2000; Vignoli et al. 2005).

\section{Results}

\section{Types and levels of asymmetry}

Core population

In the Piedras de Afilar population, both males and females showed fluctuating asymmetry in most of the analyzed traits. In traits with directional asymmetry, this was always to the left side (Tables 1 and 2). Three of the four somatic traits measured in males showed directional asymmetry (hand length, hand height and movable finger length). In females, three of the four somatic traits showed fluctuating asymmetry (hand length, hand width, and movable finger length) (Table 1). Genitalic traits had higher values of asymmetry than somatic traits (mean of genitalic traits $=6.7 \%$, mean of somatic traits of males $=1.6 \%$, mean of somatic traits of females $=2.7 \%$ ). The genital trait that showed highest levels of asymmetry was the distance of dorsal foldlateral edge (24\%). Then, length of lateral edge showed a level of asymmetry of $10 \%$, length of crest showed $9 \%$ and width of capsular lobe showed 12\% (Table 2, Figure 4).

\section{Peripheral population}

In the Mendiolaza population the results were similar. Tables 1 and 2 show that most of the analyzed traits showed fluctuating asymmetry. Somatic traits in males had fluctuating asymmetry in three of the four measured traits (hand height, hand width and movable finger length), while one had antisymmetry (hand length). Regarding somatic traits of females, two of the four measured traits showed antisymmetry (hand length and hand height), one showed fluctuating asymmetry (movable finger length) and the other showed left directional asymmetry (hand width). Genitalic traits also had higher values of fluctuating asymmetry that somatic traits in this population (mean of genitalic traits $=6.9 \%$, mean of somatic traits of males $=3 \%$, mean of somatic traits of females $=2.6 \%$ ). Distance of dorsal fold-lateral edge was the feature with highest level of asymmetry (16\%). Length of lateral edge showed a level of asymmetry of $12 \%$, length of crest showed 12\% and width of capsular lobe showed 9\% (Table 2, Figure 4).

\section{Comparison between populations}

In both studied populations, most of the analyzed traits showed fluctuating asymmetry or antisymmetry. Traits of hemispermatophores presented the highest values of fluctuating asymmetry, whereas values of somatic traits were lower. The genitalic character 'distance of dorsal fold-lateral edge' showed the greatest percentage of fluctuating asymmetry. Both populations showed values of asymmetry higher than $16 \%$ in this character (Table 2). Other important genitalic traits that showed high values in the level of asymmetry in both populations were length of lateral edge, length of crest and width of capsular lobe (Table 2, Figure 4).

Directional asymmetry in genital traits occurs in different traits of both populations. In peripheral population, length and width of the lamina showed directional asymmetry, while in the core population these traits had fluctuating asymmetry (median width of the 
860 P.A. Olivero et al.

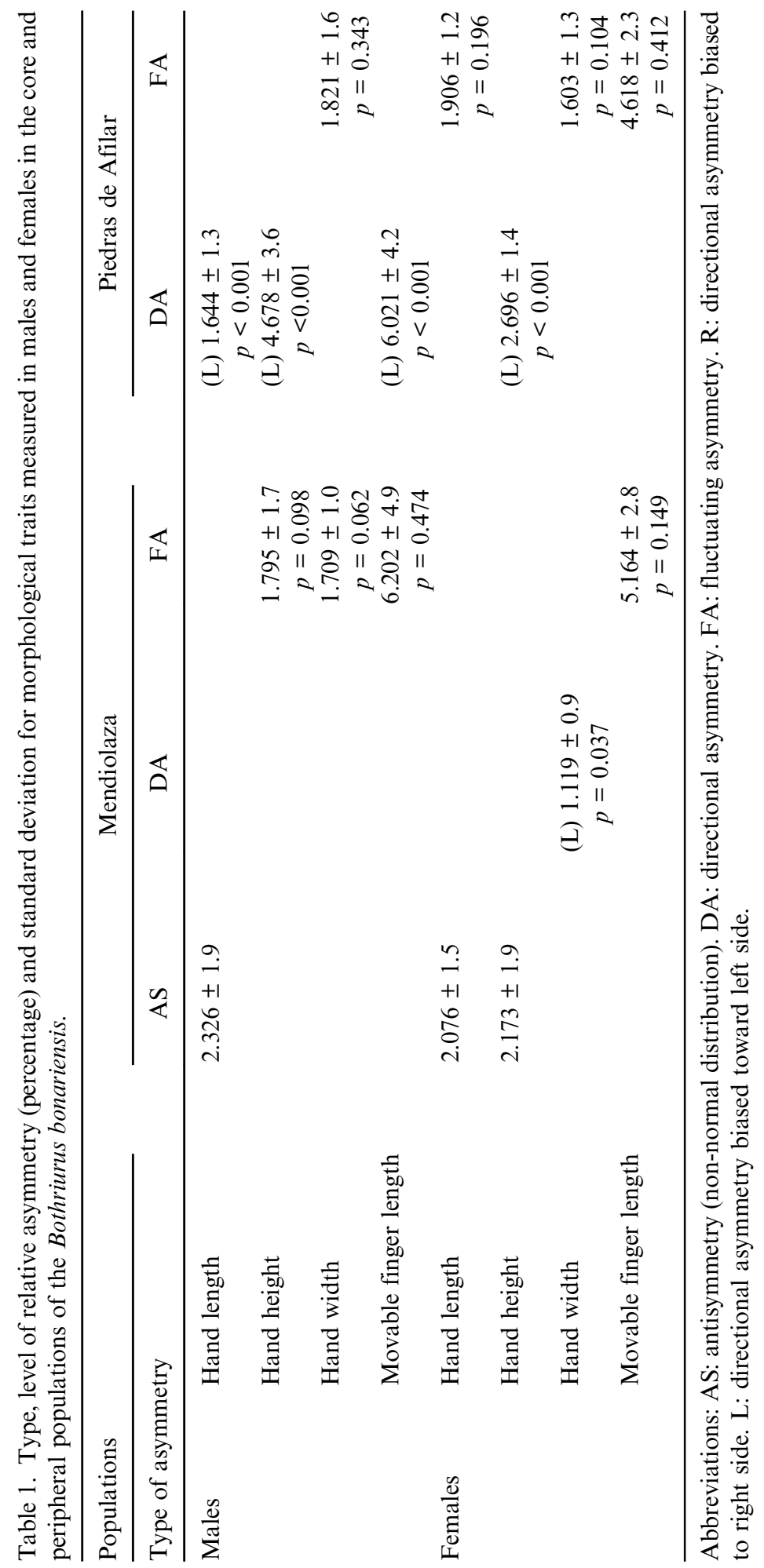




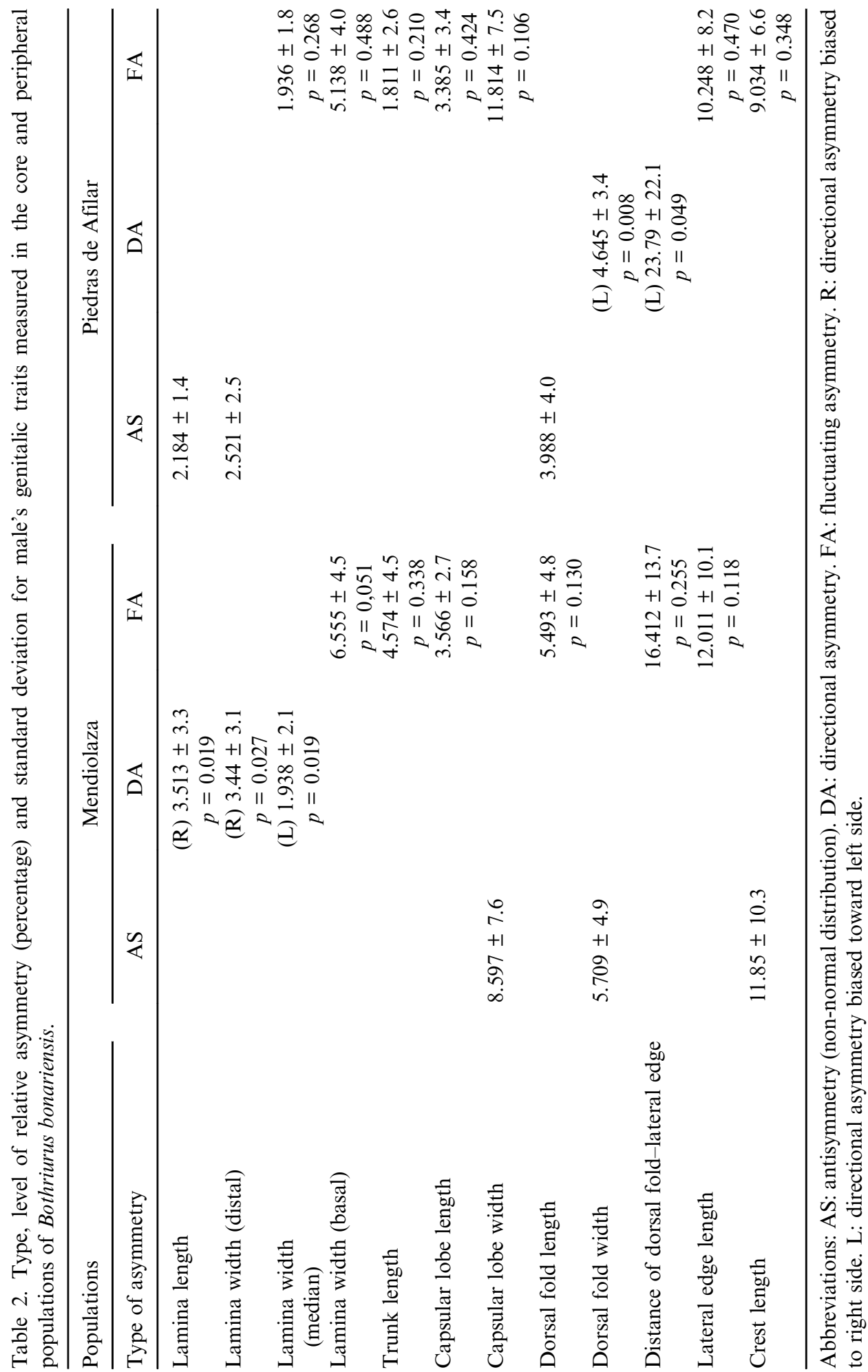




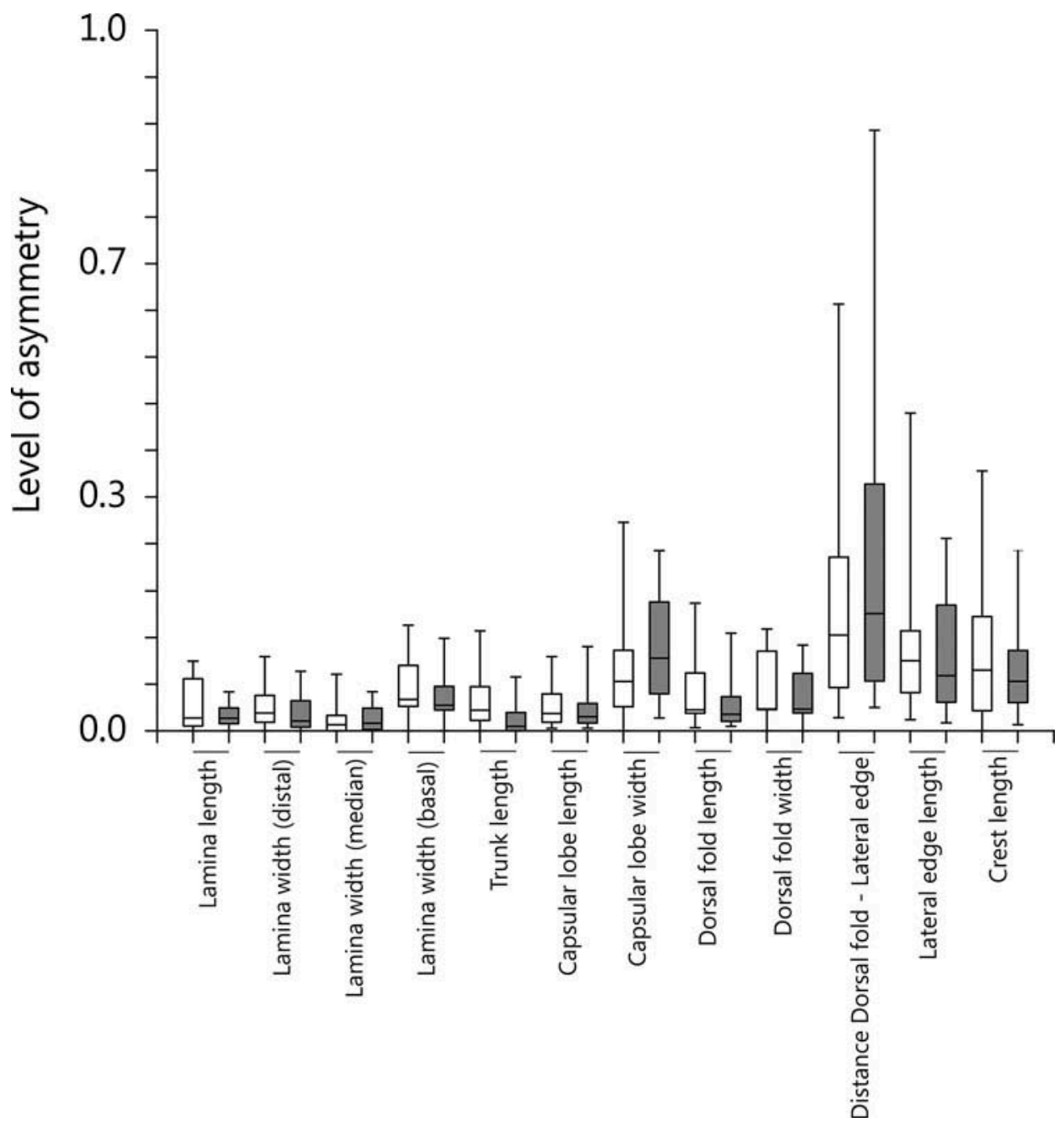

Figure 4. Level of relative asymmetry in genital traits of males of Bothriurus bonariensis in studied populations. White boxes show the values of the Mendiolaza population (peripheral), while grey boxes show the values of the Piedras de Afilar population (core).

lamina) and antisymmetry (length and distal width of the lamina). On the other hand, the core population showed directional asymmetry in traits such as dorsal fold width and distance of dorsal fold-lateral edge, whereas that in the Mendiolaza population had antisymmetry and fluctuating asymmetry, respectively (Table 2).

\section{Relationship between asymmetry and trait size}

Of three linear regressions that relate the asymmetry with trait size in peripheral population, no significant results were obtained (Table 3). However, in the core population, the length of crest showed a positive relationship between antisymmetry and trait size: antisymmetry is greater in longer hemispermatophores crests (Table 3). 
Table 3. Linear regressions between size and asymmetry of spermatophore variables of Bothriurus bonariensis.

\begin{tabular}{|c|c|c|c|c|c|c|}
\hline & Traits & $\mathrm{R}^{2}$ & Slope & Est. & $\mathrm{F}$ & $p$ \\
\hline \multirow[t]{3}{*}{ Mendiolaza } & Capsular lobe width & 0.022 & 0.209 & 0.005 & 0.365 & 0.554 \\
\hline & Lateral edge length & 0.028 & -0.089 & 0.005 & 0.494 & 0.492 \\
\hline & Crest length & 0.630 & 1.078 & 0.017 & 25.501 & 0.0001 \\
\hline \multirow[t]{3}{*}{ Piedras de Afilar } & Capsular lobe width & 0.089 & 0.323 & 0.001 & 1.369 & 0.261 \\
\hline & Lateral edge length & $<0.001$ & -0.007 & 0.015 & 0.001 & 0.969 \\
\hline & Crest length & 0.002 & 0.028 & 0.006 & 0.032 & 0.860 \\
\hline
\end{tabular}

\section{Multivariate analysis}

The discriminant analysis showed significant differences between the core and peripheral populations only for relative asymmetry of the somatic traits of males $(F=4.7, p=0.004$, Wilks lambda $=0.623$; Figure 5$)$. The most influential trait in this separation was the length of movable finger (Table 2 in Appendix). Instead, we found no significant differences between populations in genitalic traits of males $(F=1.1, p=0.448$, Wilks lambda $=0.573)$ or somatic traits of females $(F=0.5$, $p=0.714$, Wilks lambda $=0.883)$. However, genital variables of males that most

\section{Somatic traits of males}

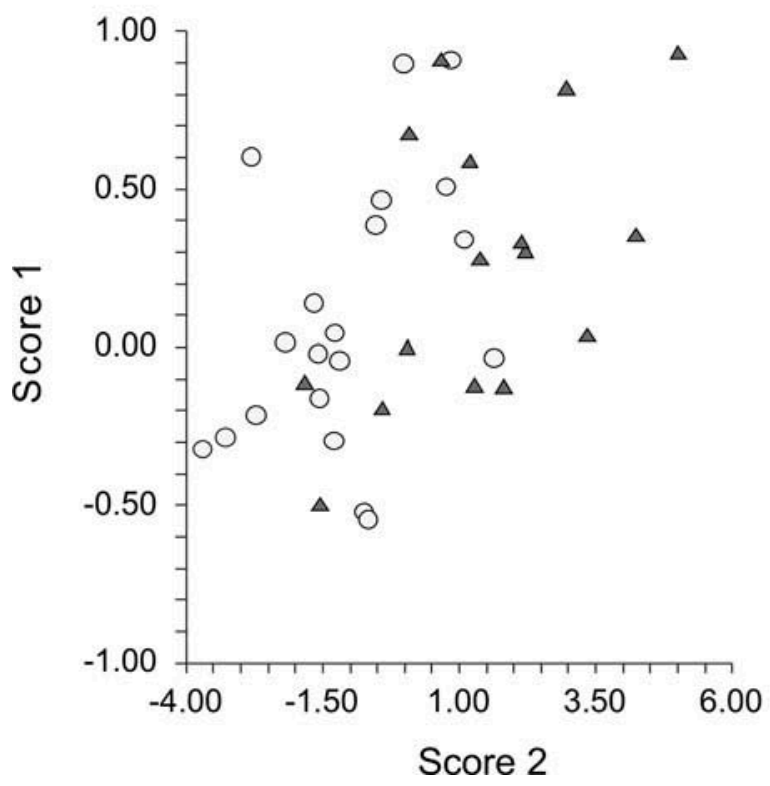

References

Mendiolaza

$\Delta$ Piedras de Afilar

Figure 5. Spatial separation of populations of Bothriurus bonariensis according somatic traits of males as Canonical Discriminant Analysis (Score 1: $F=4.7, p=0.004$, Wilk's lambda $=0.6228$. 
influenced a separation among populations were the dorsal fold length, the distance of dorsal fold-lateral edge, the length of lateral edge and the width of capsular lobe (Table 3 in Appendix). The last three also had higher values of relative asymmetry (see Table 2).

\section{Discussion}

\section{Types and levels of asymmetry}

\section{Asymmetry within populations}

Peretti et al. (2001) demonstrated that male genitalia of Bothriurus bonariensis could vary between some populations; in Argentina, males from Córdoba (peripheral distributions of the species) showed greater values of fluctuating asymmetry compared with specimens from southern Buenos Aires. In addition, in the Córdoba population, hemispermatophores are shorter as well as capsular lobes and dorsal folds, compared with population in the core of the geographic distribution (Uruguay population) of the species (Olivero et al. 2012). In this study, although we did not find differences in levels of asymmetry, we observed that types of asymmetry in genitalic traits differed in both populations. A strong developmental instability not only produces changes in the levels of fluctuating asymmetry but also translates into a transition from fluctuating asymmetry to other forms of asymmetry (Lens and Van Dongen 2000; Schneider et al. 2003; Leamy and Klingenberg 2005). Data concerning other groups of animals (Møller and Swaddle 1997) show that there could be evolutionary transitions between different types of asymmetries in response to intense directional selection. In this sense, asymmetry in hemispermatophores may reflect developmental instability, possibly due to a higher physiological sensitivity to environmental stress on the paraxial organs that produce the hemispermatophores (Peretti et al. 2001).

On the other hand, according to the discriminant analysis, somatic traits of males show a significant separation in the two populations studied, and the most influential variable in this separation is the length of movable finger. These differences could be caused by different environmental pressures in the two populations. Somatic traits analyzed in this study involved measurements of the pedipalp hands. The pedipalps are instrumental in prey capture, and they are the platform for one of the primary sensory systems in scorpions (Hjelle 1990). But also, pedipalps are sexually dimorphic and are involved in courtship, where the male leads the female in a classical promenade à deux until a suitable location is found for depositing the spermatophore and transferring sperm (Polis and Sissom 1990). For this reason, pedipalp hands also could be under the influence of sexual selection.

\section{Asymmetry of genitalic and somatic traits}

Another aspect associated with the possibility of evolutionary transitions between types of asymmetry is the following: the sister species of B. bonariensis, B. chacoensis Maury and Acosta (1993) presents a spermatophore rather similar to that of $B$. bonariensis, except that it possesses a long distal filament in the right capsular lobe. This is a case of directional asymmetry, as observed in the left lobe and other capsular structures of Brachistosternus species (Maury 1975; Acosta 1989; Peretti 1993). Some 
B. bonariensis males have rudiments of different lengths of a filament similar to that in B. chacoensis, perhaps representing different evolutionary stages (Peretti et al. 2001). This could indicate that genitalic traits in this species may be particularly sensitive to developmental instability, either by sexual selection or by stressful environmental conditions. In the present study, male genitalia shows highest levels of fluctuating asymmetry in both populations, especially in traits with an important role for sperm transfer success such as the dorsal fold, lateral edge and crest (Peretti 1992; Peretti et al. 2001; Peretti 2003). Although no significant differences were detected in fluctuating asymmetry of core and peripheral populations, the dorsal fold, lateral edge and capsular lobe are traits that may have greater influence on the separation of populations, as discriminant analysis showed. Indeed, the inner face of female operculum fits against the dorsal fold of the lamina. Along with the fit of the female operculum with the lamina, the external part of the capsule (which is represented in this stage by two capsular lobes) enters the genital atrium. This initial intromission ensures that capsular eversion takes place inside the atrium. The medial region of lamina always fits in the intercoxal space of the female's legs, and the crest helps to fit the distal part of lamina (Peretti 2003). The developmental stability of these traits could be altered as a result of sexual selection. Indeed, sexual selection can promote a greater directional selective pressure, and by this means may increase the level of developmental instability (Clarke 1997). Secondary sexual traits will show higher values of asymmetry than morphological traits under stabilizing selection (Moller 1993; Moller and Eriksson 1994; Hunt and Simmons 1998; Peretti et al. 2001; Rasmuson 2002; Vishalakshi and Singh 2006), due to the effects of genomic stress on developmental stability that are imposed by their different mode of selection (Møller and Pomiankowski 1993). Sexual selection can relax the internal mechanisms of control in the morphogenetic development of a character, leading to increased phenotypic variation and increased susceptibility to environmental stress (Moller and Hoglund 1991; Moller 1993).

On the other hand, in scorpions the hemispermatophores are formed in paired secretory sacs called 'paraxial organs' (Farley 2001). These paraxial organs, as part of the reproductive system, are present only in adult males (Hjelle 1990; Farley 2001). For this reason, the development of the hemispermatophores can be indirectly affected by environmental stresses experienced by sub-adults. Indeed, environmental pressures leading to fluctuating asymmetry may be affected by stresses at the time of sexual maturation, when the paraxial organs develop (sub-adult stage) and/or the shorter time between matings during which the each set of hemispermatophores develop (adult stage). In contrast, the pedipalp hands are present in all the stages of development and therefore the environmental pressures affect these structures throughout development. However, they are more likely to be reflective of stresses shortly before and during the moulting stages, since these are the actual stages of development of the new cuticle. Therefore, although all structures are subjected to environmental pressures, each is affected differently according to their development time.

The study of the symmetry of hemispermatophores represents an interesting area, since these structures offer an opportunity to investigate variations in the patterns of asymmetry on the adult male, where local environmental stresses may show short-term fluctuations. For example, further studies could examine the asymmetry patterns between sets of hemispermatophores produced during the male's reproductive life. 


\section{Relationship between asymmetry and trait size}

Fluctuating asymmetry has been found to be a good predictor of mating success and sexual attractiveness in fish, birds and insects (Tomkins and Simmons 2003; Gross et al. 2007). The fluctuating asymmetry may reflect the genome's ability to resist noise development, and thus indicates genetic quality. Therefore, individuals with larger and more symmetrical traits would have higher reproductive success (Andersson 1994), and females could use those traits to assess male quality (Moller 1993; Møller and Pomiankowski 1993; Andersson and Simmons 2006). Some studies have demonstrated that the production of larger traits is more expensive compared with that for smaller traits, and only bigger specimens with a better genetic value could develop symmetrical traits (Moller 1993; Møller and Swaddle 1997). However, the associations between the size and symmetry traits, especially sexual traits, have been considerably debated (Evans and Hatchwell 1993; Tomkins and Simmons 1995; Clarke 1998; Bjorksten et al. 2000).

In this study, only one of linear regressions performed had significant results, showing a positive relationship between the length of crest hemispermatophore and antisymmetry, and it has been observed that a morphological trait's size is constant, with a non-significant relation with body size (Olivero unpub. data). Therefore, it is possible that smaller specimens could produce large traits but with greater levels of asymmetry. Other studies have found no relationship between size of traits and fluctuating asymmetry (Tomkins and Simmons 1995; Hosken 2001). Another alternative could be that these levels of asymmetry may be the result of mechanical function selecting against asymmetry, and the ability of each individual to maintain symmetry during development (David et al. 1998; Hunt and Simmons 1998). Further experimental studies are needed in Bothriurus bonariensis to analyze the relationship between the asymmetry of the spermatophore with mating success, since it represents an interesting subject that is poorly understood in scorpion biology. The present work offered fundamental baseline knowledge for that purpose.

\section{Acknowledgements}

We are grateful to Carlos Toscano-Gadea and Germán Robert for help in collecting the scorpions at the field in Uruguay and Argentina, respectively. Dr. Teresa Vera and Dr. Cesar Vilardi offered valuable suggestions on early versions of this manuscript. Financial support was provided by the Consejo Nacional de Investigaciones Científicas y Técnicas (CONICET), Fondo para la Investigación Científica y Tecnológica (FONCYT) and Secretaría de Ciencia y Tecnología de la Universidad Nacional de Córdoba (SECYT). CIM and AVP are CONICET researchers.

\section{References}

Acosta LE. 1989. La fauna de escorpiones y opiliones (Arachnida) de la provincia de Córdoba [unpublished PhD thesis]. Córdoba: Facultad de Ciencias Exactas, Físicas y Naturales, Universidad Nacional de Córdoba.

Alerstam T. 1990. Bird migration. Cambridge (UK): Cambridge University Press.

Andersson M. 1994. Sexual selection. Princeton (NJ): Princeton University Press.

Andersson M, Simmons LW. 2006. Sexual selection and mate choice. Trends Ecol Evol. 21:296-302. doi:10.1016/j.tree.2006.03.015 
Auffray J-C, Renaud S, Alibert P, Nevo E. 1999. Developmental stability and adaptive radiation in the Spalax ehrenbergi superspecies in the Near-East. J Evolution Biol. 12:207-221. doi:10.1046/j.1420-9101.1999.00054.x

Băncilă R, Van Gelder I, Rotteveel E, Loman J, Arntzen JW. 2010. Fluctuating asymmetry is a function of population isolation in island lizards. J Zool. 282:266-275. doi:10.1111/j.14697998.2010.00736.x

Berggren $\AA$. 2005. Effect of propagule size and landscape structure on morphological differentiation and asymmetry in experimentally introduced Roesel's Bush-Crickets. Conserv Biol. 19:1095-1102. doi:10.1111/j.1523-1739.2005.00171.x

Bijlsma R, Loeschcke V. 2005. Environmental stress, adaptation and evolution: an overview. J Evol Biol. 18:744-749. doi:10.1111/j.1420-9101.2005.00962.x

Bjorksten TA, Fowler K, Pomiankowski A. 2000. What does sexual trait FA tell us about stress? Trends Ecol Evol. 15:163-166. doi:10.1016/S0169-5347(99)01788-7

Brown MT, Wicker LR. 2000. Discriminant analysis. In: Tinsley H, Brown S, editors. Handbook of applied multivariate statistics and mathematical modeling. San Diego (CA): Academic Press; p. 209-234.

Cabrera AL, Willink A. 1973. Biogeografía de América Latina. Monogr O.E.A, S Biol, número 13.

Clarke GM. 1997. The genetic and molecular basis of developmental stability: the Lucilia story. TREE. 12:89-91.

Clarke GM. 1998. The genetic basis of developmental stability. V. Inter- and intra-individual character variation. Heredity. 80:562-567. doi:10.1046/j.1365-2540.1998.00294.x

David P, Hingle A, Greig D, Rutherford A, Pomiankowski A, Fowler K. 1998. Male sexual ornament size but not asymmetry reflects condition in stalk-eyed flies. Proc Soc B Biol Sci. 265:2211-2216. doi:10.1098/rspb.1998.0561

Dennis R. 1993. Butterflies and climatic changes. Manchester: Manchester University Press.

Duda RO, Hart PE, Stor DG. 2001. Pattern classification. New York (NY): Wiley.

El Ouardighi A, El Akadi A, Aboutajdine D. 2007. Feature selection on supervised classification using Wilks lambda statistic. International symposium on computational intelligence and intelligent informatics - ISCIII 2007; 28-30 Mar 2007; Agadir: IEEE; p. 51-55.

Evans MR, Hatchwell BJ. 1993. New slants on ornament asymmetry. Proce Soci B Biol Sci. 251:171-177. doi:10.1098/rspb.1993.0025

Farley R. 2001. Structure, reproduction and development. In: Brownell P, Polis GA, editors. Scorpion biology and research. Oxford (UK): Oxford University Press; p. 13-78.

Fisher RA. 1936. The use of multiple measurements in taxonomic problems. Ann Eugenics. 7:179-188. doi:10.1111/j.1469-1809.1936.tb02137.x

Fukunaga K. 1990. Introduction to statistical pattern recognition. 2nd ed. Boston (MA): Academic Press.

Graham JH, Fletcher D, Tigue J, McDonald M. 2000. Growth and developmental stability of Drosophila melanogaster in low frequency magnetic fields. Bioelectromagnetics. 21:465472. doi:10.1002/1521-186X(200009)21:6<465::AID-BEM6>3.0.CO;2-C

Graham JH, Roe KE, West TB. 1993. Effects of lead and benzene on the developmental stability of Drosophila melanogaster. Ecotoxicology. 2:185-195. doi:10.1007/BF00116423

Gross MR, Suk HY, Robertson CT. 2007. Courtship and genetic quality: asymmetric males show their best side. Proce Soc B Biol Sci. 274:2115-2122.

Helle S, Huhta E, Suorsa P, Hakkarainen H. 2011. Fluctuating asymmetry as a biomarker of habitat fragmentation in an area-sensitive passerine, the Eurasian treecreeper (Certhia familiaris). Ecol Indic. 11:861-867. doi:10.1016/j.ecolind.2010.11.004

Hendrickx F, Maelfait JP, Lens L. 2003. Relationship between fluctuating asymmetry and fitness within and between stressed and unstressed populations of the wolf spider Pirata piraticus. J Evol Biol. 16:1270-1279. doi:10.1046/j.1420-9101.2003.00633.x 
Henríquez P, Donoso DS, Grez AA. 2009. Population density, sex ratio, body size and fluctuating asymmetry of Ceroglossus chilensis (Carabidae) in the fragmented Maulino forest and surrounding pine plantations. Acta Oecol. 35:811-818. doi:10.1016/j. actao.2009.08.012

Hjelle JT. 1990. Anatomy and morphology. In: Polis GA, editor. The biology of scorpions. Stanford (CA): Stanford University Press; p. 9-63.

Hosken DJ. 2001. Size and fluctuating asymmetry in sexually selected traits. Anim Behav. 62:603-605. doi:10.1006/anbe.2001.1809

Huber BA, Sinclair BJ, Schmitt M. 2007. The evolution of asymmetric genitalia in spiders and insects. Biol Rev. 82:647-698. doi:10.1111/j.1469-185X.2007.00029.x

Hunt J, Simmons LW. 1998. Patterns of fluctuating asymmetry in beetle horns: no evidence for reliable signaling. Behav Ecol. 9:465-470. doi:10.1093/beheco/9.5.465

Kark S. 2001. Shifts in bilateral asymmetry within a distribution range: the case of the chukar partridge. Evolution. 55:2088-2096. doi:10.1111/j.0014-3820.2001.tb01323.x

Kark S, Lens L, Van Dongen S, Schmidt E. 2004. Asymmetry patterns across the distribution range: does the species matter? Biol J Linn Soc. 81:313-324. doi:10.1111/j.10958312.2004.00296.x

Leamy L, Klingenberg CP. 2005. The genetics and evolution of fluctuating asymmetry. Annu Rev Ecol Syst. 36:1-21. doi:10.1146/annurev.ecolsys.36.102003.152640

Lens L, Van Dongen S. 2000. Fluctuating and directional asymmetry in natural bird populations exposed to different levels of habitat disturbance, as revealed by mixture analysis. Ecol Lett. 3:516-522. doi:10.1046/j.1461-0248.2000.00181.x

Leung B, Knopper L, Mineau P. 2003. A critical assessment of the utility of fluctuating asymmetry as a biomarker of anthropogenic stress. In: Polak M, editor. Developmental instability: causes and consequences. Oxford (UK): Oxford University Press; p. 415-426.

Lourenço WR, Cloudsley-Thompson JL. 1996. The evolutionary significance of colour, colour patterns and fluorescence in scorpions. Revue Suisse Zool. 2:449-458.

Mattoni CI. 2002. Bothriurus pichicuy, nuevo escorpión chileno del grupo vittatus (Scorpiones, Bothriuridae). Iheringia, Ser Zool. 92:81-87. doi:10.1590/S0073-47212002000400010

Mattoni CI. 2003. Patrones evolutivos en el género Bothriurus (Scorpiones, Bothriuridae): análisis filogenético [doctoral thesis]. Córdoba: Facultad de Ciencias Exactas, Físicas y Naturales, Universidad Nacional de Córdoba.

Mattoni CI, Acosta LE. 2005. A new species of Bothriurus from Brazil (Scorpiones, Bothriuridae). J Arachnol. 33:735-744. doi:10.1636/H04-31.1

Maury EA. 1975. La estructura del espermatóforo en el género Brachistosternus (Scorpiones, Bothriuridae). Phisys Sec C. 34:179-182.

Maury EA, Acosta LE. 1993. Un nuevo Botrhiurus de grupo bonariensis (Scorpiones, Bothriuridae). B Soc Bio Concepción. 64:39-45.

Mayr E. 1942. Systematics and the origin of species, from the viewpoint of a zoologist. Cambridge (MA): Harvard University Press.

McNab BK. 1973. Energetics and the distribution of vampires. J Mammal. 54:131-144. doi: $10.2307 / 1378876$

Moller AP. 1993. Morphology and sexual selection in the barn swallow Hirundo rustica in Chernobyl, Ukraine. Proc Soc B Biol Sci. 252:51-57. doi:10.1098/rspb.1993.0045

Moller AP. 1995. Patterns of fluctuating asymmetry in sexual ornaments of birds from marginal and central populations. Am Nat. 145:316-327. doi:10.1086/285742

Møller AP. 1997. Developmental stability and fitness: a review. Am Nat. 149:916-932. doi:10.1086/286030

Moller AP, Eriksson M. 1994. Patterns of fluctuating asymmetry in flowers: implications for sexual selection in plants. J Evol Biol. 7:97-113. doi:10.1046/j.1420-9101.1994.7010097.x 
Moller AP, Hoglund J. 1991. Patterns of fluctuating asymmetry in avian feather ornaments: implications for models of sexual selection. Proc Soc B Biol Sci. 245:1-5. doi:10.1098/ rspb. 1991.0080

Moller AP, Magnhagen C, Ulfstrand A, Ulfstrand S. 1995. Phenotypic quality and molt in the barn swallow, Hirundo rustica. Behav Ecol. 6:242-249. doi:10.1093/beheco/6.3.242

Møller AP, Pomiankowski A. 1993. Fluctuating asymmetry and sexual selection. Genetica. 89:267-279. doi:10.1007/BF02424520

Møller AP, Swaddle JP. 1997. Asymmetry, developmental stability and evolution. Oxford (UK): Oxford University Press.

Ojanguren Affilastro AA. 2005. Estudio monográfico de los escorpiones de la República Argentina. Rev Iber Aracnol. 11:74-246.

Olivero PA, Mattoni CI, Peretti AV. 2012. Morphometry and geographical variation of Bothriurus bonariensis (Scorpiones: Bothriuridae). J Arachnol. 40:113-122. doi:10.1636/ B11-27.1

Palmer AR. 2004. Symmetry breaking and the evolution of development. Science. 306:828-833. doi:10.1126/science. 1103707

Palmer AR. 2005. Antisymmetry. In: Hallgrimmson B, Hall BK, editors. Variation. Amsterdam: Elsevier; p. 359-397.

Palmer AR, Strobeck C. 1992. Fluctuating asymmetry as a measure of developmental stability: implications of non-normal distributions and power of statistical test. Acta Zool Fenn. 191:57-72.

Palmer AR, Strobeck C. 2003. Fluctuating asymmetry analyses revisited. In: Polak M, editor. Developmental instability (DI): causes and consequences. Oxford (UK): Oxford University Press; p. 279-319.

Parsons PA. 1993. The importance and consequences of stress in living and fossil populations: from life-history variation to evolutionary change. Am Nat. 142:5-20. doi:10.1086/285520

Peretti AV. 1992. El espermatóforo de Bothriurus bonariensis (C. L. Koch) (Sc., Bothriuridae). B Soc Biol Concepción. 63:125-138.

Peretti AV. 1993. Estudio de la biología reproductiva en escorpiones argentinos (Arachnida, Scorpiones): un enfoque etológico [unpublished $\mathrm{PhD}$ thesis]. Córdoba: Facultad de Ciencias Exactas, Físicas y Naturales, Universidad Nacional de Córdoba.

Peretti AV. 1995. Análisis de la etapa inicial del cortejo de Bothirurus bonariensis (Scorpiones, Bothriuridae) y se relación con el reconocimiento sexual. Rev Arachnol. 11:35-45.

Peretti AV. 2003. Functional morphology of spermatophores and female genitalia in bothriurid scorpions: genital courtship, coercion and other possible mechanisms. J Zool. 261:135153. doi:10.1017/S095283690300400X

Peretti AV, Depiante ML, Battán Horenstein M. 2001. Petterns of allometry and asymmetry of body characters and spermatophores in Bothriurus bonariensis (C.L. Koch, 1842) (Scorpiones: Bothriuridae). In: Fet V, Seldem P, editors. Scorpions 2001. In Memoriam Gary A. Polis. London: British Arachnological Society; p. 345-355.

Picton HD, Palmisciano D, Nelson G. 1990. Fluctuating asymmetry and testing isolation of Montana grizzli bear populations. Int C Bear. 8:421-424.

Polis GA, Sissom WD. 1990. Life history. In: Polis GA, editor. The biology of scorpions. Stanford (CA): Stanford University Press; p. 161-223.

Pomiankowski A, Iwasa Y, Nee S. 1991. The evolution of costly mate preferences. I. Fisher and biased mutations. Evolution. 45:1422-1430. doi:10.2307/2409889

Rasmuson M. 2002. Fluctuating asymmetry - indicator of what? Hereditas. 136:177-183. doi:10.1034/j.1601-5223.2002.1360301.x

Root T. 1988a. Environmental factors associated with avian distributional boundaries. J Biogeogr. 15:489-505. doi:10.2307/2845278

Root T. 1988b. Energy constraints on avian distributions and abundances. Ecology. 69:330 339. doi:10.2307/1940431 
Santos M. 2001. Fluctuating asymmetry is nongenetically related to mating success in Drosophila buzzatii. Evolution. 55:2248-2256. doi:10.1111/j.0014-3820.2001.tb00739.x

Santos M, Brites D, Laayouni H. 2006. Thermal evolution of pre-adult life history traits, geometric size and shape, and developmental stability in Drosophila subobscura. J Evol Biol. 19:2006-2021. doi:10.1111/j.1420-9101.2006.01139.x

Schneider SS, Leamy LJ, Lewis LA, De Grandi-Hoffman G. 2003. The influence of hybridization between African and European honeybees, Apis mellifera, on asymmetries in wing size and shape. Evolution. 57:2350-2364. doi:10.1111/j.0014-3820.2003.tb00247.x

Siegel S, Catellan NJ. 1988. Nonparametric statistics for the behavioral sciences. 2nd ed. New York (NY): McGraw-Hill.

Sissom WD, Polis GA, Watt DD. 1990. Field and laboratory methods. In: Polis GA, editor. The biology of scorpions. Stanford (CA): Stanford University Press; p. 445-461.

Swaddle JP, Witter MS, Cuthill IC. 1994. The analysis of fluctuating asymmetry. Anim Behav. 48:986-989. doi:10.1006/anbe.1994.1327

Timofeeff-Ressovsky NV. 1934. Über der Einfluss des genotypischen Milieus und der Aussenbendigungen auf die Realisation des Genotypes. Genmutation vti bei Drosophila funebris. Nachr Acad Wiss Göttingen II. 61:53-106.

Tomkins JL, Simmons LW. 1995. Patterns of fluctuating asymmetry in earwig forceps: no evidence for reliable signalling. Proc Soc B Biol Sci. 259:89-96. doi:10.1098/ rspb.1995.0014

Tomkins JL, Simmons LW. 2003. Fluctuating asymmetry and sexual selection: paradigms shifts, publication bias and observer expectation. In: Polak M, editor. Developmental instability: causes and consequences. Oxford (UK): Oxford University Press; p. 231-261.

Uetz GW, Roberts JA, Wrinn KM, Polak M, Cameron GN. 2009. Impact of a catastrophic natural disturbance on fluctuating asymmetry (FA) in a wolf spider. Ecoscience. 16:379386. doi:10.2980/16-3-3261

Van Valen L. 1962. A study of fluctuating asymmetry. Evolution. 16:125-142. doi:10.2307/ 2406192

Vignoli V, Salomone N, Caruso T, Bernini F. 2005. The Euscorpius tergestinus (C.L. Koch, 1837) complex in Italy: biometrics of sympatric hidden species (Scorpiones: Euscorpiidae). Zoologischer Anzeiger - J Comp Zool. 244:97-113. doi:10.1016/j.jcz.2005.05.002

Vishalakshi C. 2011. Fluctuating asymmetry in Drosophila. Low Temp Sci. 69:51-60.

Vishalakshi C, Singh BN. 2006. Fluctuating asymmetry in certain morphological traits in laboratory populations of Drosophila ananassae. Genome. 49:777-785. doi:10.1139/G06031

Vishalakshi C, Singh BN. 2008a. Effect of environmental stress on fluctuating asymmetry in certain morphological traits in Drosophila ananassae: nutrition and larval crowding. Can J Zool. 86:427-437. doi:10.1139/Z08-010

Vishalakshi C, Singh BN. 2008b. Effect of developmental temperature stress on fluctuating asymmetry in certain morphological traits in Drosophila ananassae. J Therm Biol. 33:201208. doi:10.1016/j.jtherbio.2007.09.004

Vishalakshi C, Singh BN. 2008c. Mating success is not correlated with fluctuating asymmetry in Drosophila ananassae. Cur Sci. 94:377-381. 


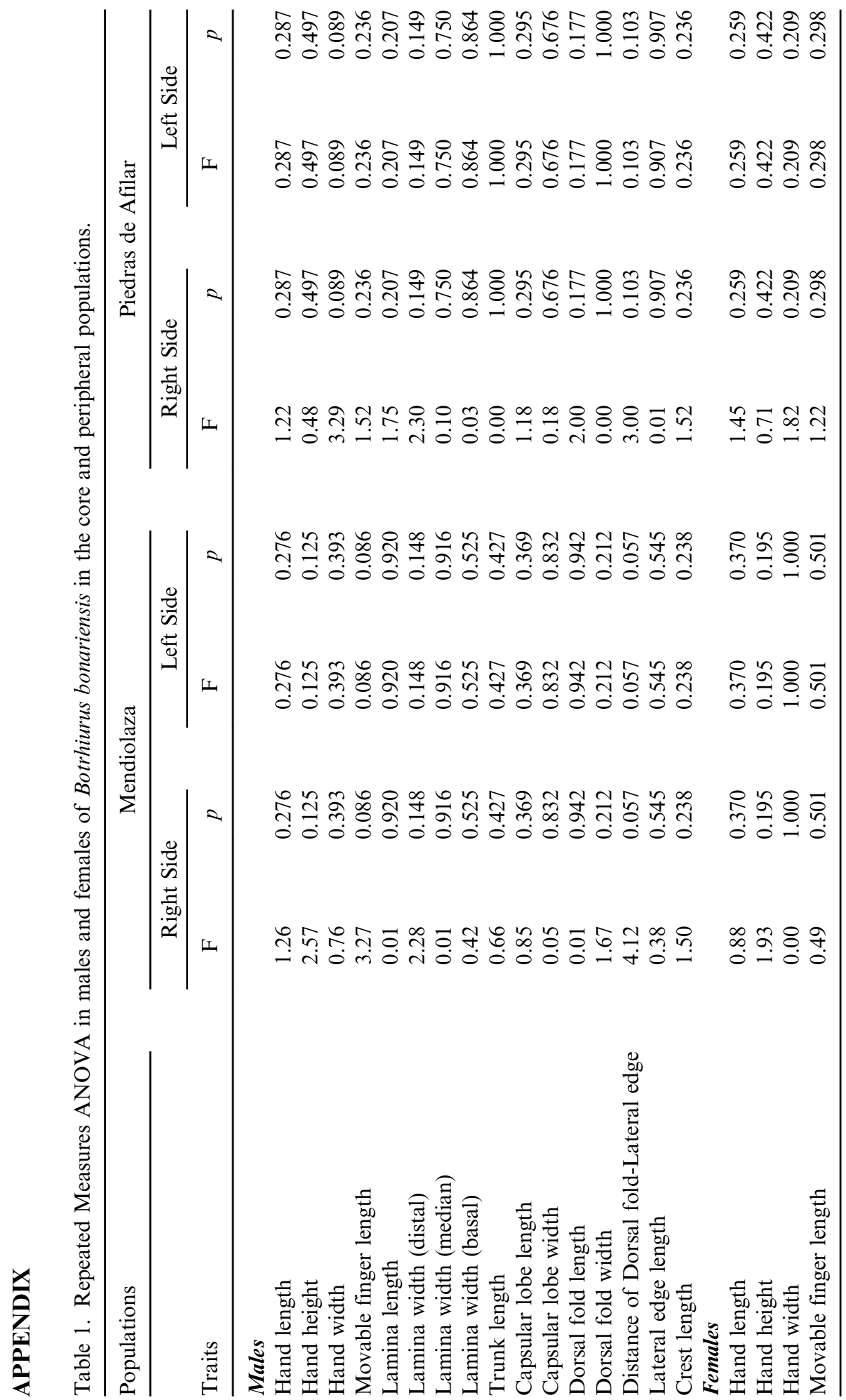


Table 2. Influence of somatic traits analyzed in the Canonical Discriminant Analysis in males of the studied populations of Bothriurus bonariensis.

\begin{tabular}{lcc}
\hline & Variable Influence Section & \\
\hline Variable & $\mathrm{F}$ & $p$ \\
\hline Movable finger length & 14.57 & 0.0005 \\
Hand heigth & 12.41 & 0.0012 \\
Hand length & 4.89 & 0.0338 \\
Hand width & 0.35 & 0.5567 \\
\hline
\end{tabular}

Table 3. Influence of genital traits considered in the Canonical Discriminant Analysis for group separation in males of the studied populations of Bothriurus bonariensis.

\begin{tabular}{llc}
\hline \multicolumn{2}{c}{ Variable Influence Section } & \\
\hline Variable & $\mathrm{F}$ & $p$ \\
\hline Dorsal fold length & 2.27 & 0.143 \\
Distance of dorsal fold-lateral edge & 1.91 & 0.178 \\
Lateral edge length & 1.5 & 0.230 \\
Capsular lobe width & 1.31 & 0.262 \\
Lamina length & 1.15 & 0.292 \\
Lamina width (distal) & 1.06 & 0.313 \\
Lamina width (basal) & 0.94 & 0.341 \\
Lamina width (medial) & 0.84 & 0.366 \\
Trunk length & 0.68 & 0.415 \\
Crest length & 0.37 & 0.549 \\
Dorsal fold width & 0.24 & 0.630 \\
Capsular lobe length & 0.17 & 0.686 \\
\hline
\end{tabular}

